\title{
Una reflexión sobre el Estado: la vuelta a los clásicos del marxismo*
}

Luis Armando González**

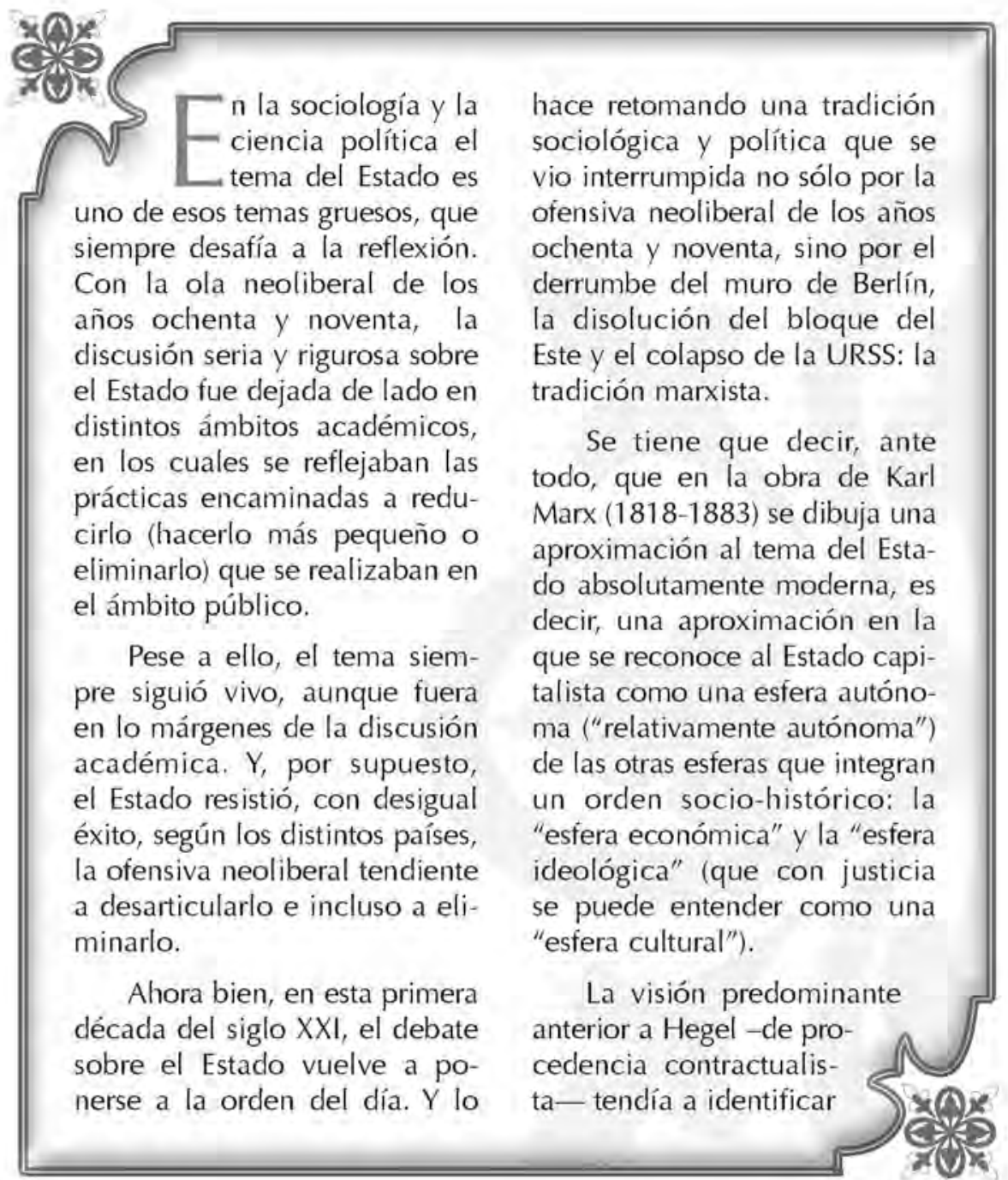


Estado y sociedad: el contrato social era establecido por los individuos para formar un Estado, antes del cual no formaban cuerpo social alguno, sino que más bien estaban en una guerra de todos contra todos. En todo caso, si se aceptaba la existencia de un orden social distinto del Estado, el mismo era una creación ulterior de este último; primero se constituía el Estado y luego se creaba la sociedad, en virtud de un contrato del cual aquél era el garante último.

Marx, siguiendo a Hegel -como él mismo lo reconoce en distintos textos - no acepta ni que la sociedad sea igual al Estado ni que éste sea el creador de aquélla. Antes bien, sucede lo contrario: siguiendo a Hegel, para Marx la "sociedad civil", como ámbito de las relaciones familiares, la actividad práctica económica y el intercambio (la sociedad civil como el "verdadero hogar y escenario de toda la historia"1) es históricamente anterior al Estado, siendo este último una derivación de los dinamismos que se generan en ella. Estos dinanismos son los dinamismos de clase, cuya raíz está en el proceso de producción material. Es decir, "la organización social y el Estado brotan constantemente del proceso de vida de determinados individuos; pero de estos individuos, no como puedan presentarse ante la imaginación propia o ajena, sino como realmente son... tal y como actúan y como producen materialmente $y$, por tanto, tal y como desarrollan sus actividades baja de- terminados límites, premisas y condiciones materiales, independientes de su voluntad"2.

En la perspectiva de Marx, el Estado surge cuando se configuran las clases sociales (cuyo anclaje está en la base económica de la sociedad), una de las cuales -la dominante-necesita de él para mantener su dominio sobre las clases subordinadas. El Estado, en este sentido, es un "instrumento" de dominación; un instrumento al servicio de la clase dominante.

"La burguesía -dice Marx en La ideología alemana-, por ser ya una clase, y no un simple estamento, se halla obligada a organizarse en un plano nacional y no ya solamente en un plano local y a dar a su interés medio unas forma general. Mediante la emancipación de la propiedad privada con respecto a la comunidad, el Estado cobra una existencia especial junto a la sociedad civil y al margen de ella; pero no es tampoco más que la forma de organización a que necesariamente șe someten los burgueses, tanto en lo interior como en lo exterior, para la mutua garantía de su propiedad y de sus intereses... Como el Estado es la forma bajo la que los individuos de una clase dominante hacen valer sus intereses comunes y en Ia que se condensa toda la sociedad civil de una época, se sigue de aquí que todas las instituciones comunes tienen como mediador al Estado y adquieren a través de él una forma política. De ahí la ilusión de que la ley se basa en la voluntad $y_{\text {, }}$ ade- 
más, en la voluntad desgajada de su base real, en la voluntad libre. $Y$, del mismo modo, se reduce el derecho, a su vez, a la ley"3.

Pero el Estado, en Marx, no es un todo uniforme, sino que consta de dos momentos: (a) el legal, formado por un corpus juridico-normativo mediante el cual se legaliza (y legitima) la desigualdad de clases existente en la esfera económica (y en el cual los desiguales aparecen como iguales); y (b) el coercitivo, que entra en acción, apelando a los recursos de fuerza que monopoliza el Estado, cuando la ley falla en su función de mantener resguardados los intereses de la clase dominante.

Así pues, el Estado es una pieza fundamental en la dominación de una clase sobre el resto de la sociedad. También lo es la ideología, pues para Marx -en la célebre definición ofrecida en La ideología alemana- la ideología dominante es la ideología de la clase dominante. O como él lo dice, "las ideas de la clase dominante son las ideas dominantes en cada época; o, dicho en otros términos, la clase que ejerce el poder material dominante en la sociedad es, al mismo tiempo, su poder espiritual dominante. La clase que tiene a su disposición los medios para la producción material dispone con ello, al mismo tiempo, de los medios para la producción espiritual, lo que hace que se le sometan, al propio tiempo, por término medio, las ideas de quienes carecen de los medios necesarios para producir espiritualmente $e^{\prime 4}$.
Por eso, la lucha contra la dominación se libra -además de en el terreno ideológico-, en el plano político, en contra del Estado y por su control, siendo esto último clave en un proceso de cambio revolucionario. Porque "toda clase que aspire a implantar su dominación, aunque ésta, como ocurre en el caso del proletariado, condicione en absoluto la abolición de toda la forma de la sociedad anterior y de toda dominación en general, tiene que empezar conquistando el poder político, para poder presentar su interés como el interés general"s.

En la visión de Marx, una de las vías posibles para hacerse del control del Estado es la vía democrático-electoral, pero ella se enmarca en la legalidad burguesa $y$, en consecuencia, está limitada por ella y-como dice él en la Crítica al Programa de Gotha- por su "letanía democrática": sufragio universal, legislación directa, derecho popular y milicia del pueblo ${ }^{6}$. La otra vía es la revolucionaria, que supone el asalto violento del Estado por parte de la clase proletaria organizada en un partido comunista. Este asalto es necesario para que la clase en ascenso subordine el aparato estatal a sus propios fines. Dicho sea de paso, Friedrich Engels, en su testamento político, hizo una apuesta por la primera de las opciones apuntadas, abriendo las puertas al desarrollo de la socialdemocracia alemana.

Como quiera que sea, en la perspectiva de Marx, la conquista 
del Estado por parte de la clase proletaria tiene una finalidad última: conducirlo a su abolición definitiva, lo cual supone la abolición de la raíz económica de las divisiones de clase: la propiedad privada de los medios de produccion. En la fase socialista del proceso revolucionario, el proletariado creará -mediante la "dictadura revolucionaria del proletariado" - las condiciones que permitan arribar al comunismo como la etapa más plena del desarrollo histórico de la humanidad, una etapa en las cual las clases sociales habrán desaparecido y, por consiguiente, el Estado será innecesario desde un punto de vista social, político y económico. "Entre la sociedad capitalista y la sociedad comunista - escribe Marx - media el periodo de transformación revolucionaria de la primera en la segunda. A este periodo corresponde también un periodo político de transición, cuyo Estado no puede ser otro que la dictadura revolucionaria del proletariado" después se transitará a la sociedad comunista, "donde cada individuo no tiene acotado un círculo exclusivo de actividades, sino que puede desarrollar sus aptitudes en la rama que mejor le parezca, la sociedad se encarga de regular la producción general, con lo que hace cabalmente posible que yo pueda hoy a esto y mañana a aquello, que pueda por la mañana cazar, por la tárde pescar y por la noche apacentar ganado, y después de comer, si me place, dedicarme a criticar, sin necesidad de ser exclusivamente cazador, pescador, pastor o crítico, según los casos $^{\prime \prime}$.

En resumen, Marx enfatizó la dimensión instrumental del Estado, lo cual fue un acierto, pues no podemos obviar la evidencia histórica que respalda el uso del Estado por parte de grupos de poder económico. Pero la visión de Marx es insuficiente, porque el Estado es, además de instrumento de dominación, otras muchas cosas. Para el caso, no prestó atención al peso del Estado en la configuración del orden social, sobre todo en lo que hace no sólo a su influencia normativa, sino a su influencia en las conductas, hábitos, estilos de comportamiento, valoraciones y creencias de hombres y mujeres que viven bajo su jurisdicción e incluso -en el caso de estados predominantes en el escenario mundial- fuera de ella.

No hay mejor ejemplo de esto último que el enorme peso que tuvo el Estado soviético en la configuración de las sociedades del bloque del Este, desde 1945 hasta 1989. $\mathrm{O}$, la contrapartida occidental de un influjo semejante por parte de Estados Unidos, el cual en la actualidad se ha extendido - muchas veces mediante mecanismos de terror y violencia-, por el mundo. Más cerca de nosotros, está el indiscutible influjo de los estados militarizados latinoamericanos -durante la mayor parte del siglo XX - sobre los hábitos, conductas y creencias de la gente. Una cultura política autoritaria germinó y se desarrolló a partir de ese influjo, sin que hasta ahora 
haya podido ser contrarresta por una cultura política democrática.

En la tradición marxista, el autor que más se acercó a una comprensión del Estado como generador de cultura, y no sólo cómo un instrumento de dominación, fue Antonio Gramsci (1891-1937). Cabe recordar que Vladimir Lenin (1870-1924) continuó la línea de interpretación de Marx, es decir, la de entender al Estado como un instrumento de clase. Pero Gramsci tuvo al acierto de distanciarse de esta interpretación que era (y siguió siendo la predominante durante mucho tiempo) la predominante en los círculos marxistas.

El filósofo italiano entendió al Estado como una instancia atravesada por una doble dimensión: la hegemonía y la coerción. En sus palabras: "hay que observar que en la noción general de Estado intervienen elementos que hay que reconducir a la noción de sociedad civil (en el sentido, pudiera decirse, de que Estado = sociedad política + sociedad civil, o sea, hegemonía acorazada de coacción)" ${ }^{\prime \prime}$. La sociedad civil ya no tiene que ver con las prácticas sociales -tal como lo entiende Marx - sino con la capacidad del Estado para asegurar la hegemonía de una clase sobre el conjunto de la sociedad, es decir, para asegurar que la clase en el poder no sólo "dominé", sino que también "dirija" a la sociedad. "El hecho de la hegemonía presupone, sin duda -dice Gramsci-, que se tengan en cuenta los intereses y las tendencias de los grupos sobre los cuales se ejercerá la hegemonía, que se constituya un cierto equilibrio de compromisos"10.

Ese "equilibrio de compromi$\operatorname{sos}^{\prime \prime}$ supone la capacidad del Estado para generar consenso en torno al proyecto de la clase dominante. En virtud de ello, el Estado puede dotarse de legitimidad "convenciendo" a los ciudadanos y ciudadanas de que lo suyo es el "bien común" y el "interés general", y no el interés de una clase o un grupo en particular. Este convencimiento da estabilidad política a la sociedad y asegura el orden social, lo cual significa que el proyecto de la clase dominante es aceptado voluntariamente por las clases subordinadas. Cuando esta capacidad de convencimiento falla, entonces entran en juego los mecanismos coercitivos del Estado, que ponen en evidencia una situación de crisis política. Cuando esto sucede, la sociedad civil es desplazada por la sociedad política, que no es otra cosa que la dimensión coercitiva del Estado.

Gramsci nos acercó, de esta manera, a una visión más compleja de la estructura del Estado y sus funciones. Lamentablemente, la visión de Lenin -convertida en dogma de fe gracias a la labor de Stalin y los hacedores de manuales de la desaparecida Academia de Ciencias de la URSS - fue la que se impuso, prácticamente hasta la desaparición de la URSS, en el debate marxista. De esta manera, se impidió que la interpretación de Gramsci se abrie- 
ra paso y marcara la pauta de la discusión teórica sobre el Estado. De aquí que la recuperación de Gramsci sea uno de los desafíos más importantes en el debate marxista actual.

Pero no basta con retomar a Gramsci, para avanzar hacia aproximación teórica más rigurosa sobre el Estado. Para empezar, la interpretación del Estado como instrumento de clase debe ser revisada críticamente, para ponderar qué tan realista es suponer que el Estado sea un ente manipulable que puede ser usado por una clase para sus propios fines, o incluso que puede ser abolido por la voluntad colectiva en un determinado momento histórico.

Hay que hacerse cargo de la realidad del Estado como un aparato burocrático no sólo capaz de mantenerse en el tiempo, sino capaz de crecer y acumular poder (normativo, institucional, simbólico y material) si se lo deja a sus propia suerte, y ya no se diga si expresamente se impulsan prácticas políticas que lo hagan crecer y desarrollarse (tal como sucedió en la ex URSS, con el Estado de bienestar occidental y con los estados populistas latinoamericanos de los años 40 y 50 del siglo XX).

Pocos ataques contra el Estado han sido tan feroces como los realizados por los reformadores neoliberales, que se propusieron, en su momento de más éxito (años 80 y 90 del siglo XX), cumplir el sueño de Marx: abolir el Estado, no socializándolo -como quería el filósofo alemán-, sino privatizando sus empresas, funciones y servicios.

Pero el Estado resistió y siguió en pie. $Y$ en estos momentos en el marco de la actual crisis financiera mundial - se ha puesto en la mesa de discusión la necesidad de fortalecerlo, tanto en sus funciones económicas como en sus funciones sociales. Asimismo, por el lado latinoamericano, la resistencia al neoliberalismo de inicios del siglo XXI ha supuesto no sólo un protagonismo social, sino también un protagonismo estatal.

En definitiva, no se quiere decir aquí que el Estado sea una sustancia eterna e inamovible. Nada más se señala que el Estado tiene una enorme capacidad de mantenerse en el tiempo, cambiando, pero conservando su identidad fundamental. Una identidad que se ha forjado y cristálizado a lo largo de la historia de cada sociedad, lo cual convierte al Estado en una realidad resistente no a lo pequeños cambios (que se suceden regularmente), sino a las grandes transformaciones, que sobrevienen en el marco de transformaciones sociales, económicas y políticas más amplias... Y aún así, suelen quedar vestigios del Estado que ha sido demolido, tal como sucedió en la Rusia revolucionaria posterior a 1917 y sucede en la Rusia actual, una vez que, después de 1991, el socialismo real fue reemplazado por el capitalísmo neoliberal. 
En enfoque de sistemas se impone como recurso teórico para entender al Estado". Visto como un sistema, el Estado tiene una capacidad de autoreproducción propia de cualquier sistema. Cambia, pero se mantiene en su identidad. $Y$ se desintegra totalmente, cuando ya no es capaz de autoreproducirse, o sea, cuando ya no es capaz de asimilar los recursos que el entorno le ofrece para ello. Al suceder esto, un nuevo Estado (un nuevo sistema estatal) puede entrar en escena. Estas transformaciones sistémicas-estatales no han sido tan frecuentes en las sociedades conocidas, pero cuando se han dado las han marcado de manera indeleble, reencauzándolas por trayectorias distintás a las que habían seguido hasta entonces. En suma, para la compresión teórica del Estado quizá sea útil tomar en cuenta esta afirmación de Mario Bunge acera de los sistemas.

"La estructura, en especial la interna -dice este autor-, es esencial para los sistemas. En efecto, para explicar la emergencia de un sistema debemos descubrir el correspondiente proceso de combinación o ensamblado y, particularmente, los vínculos o enlaces resultantes de la formación de la totalidad. Lo mismo vale, mutatis mutandis, para cualquier explicación de la descomposición de un sistema. En otras palabras, explicamos la emergencia, el comportamiento y la desintegración de los sistemas, no sólo en términos de su composición y entorno, sino también en términos de su estructura total (interna y externa). $Y$ esto no es suficiente: es necesario conocer algo acerca del mecanismo o modus operandi del sistema, vale decir, del proceso que lo hace comportarse - 0 dejar de comportarse - del modo en que lo hace $\mathrm{e}^{\prime \prime 22}$.

*Texto modificado de la charla ofrecida por el autor a estudiantes de licenciatura en Sociología de la UES, en el marco del curso "Estado, gobierno y sociedad". San Salvador, 22 de abril de 2009. Una primera versión de estas ideas se desarrolló en el curso de "Historia económica" impartido por el autor en la UCA, en el primer semestre de 2009.

** Licenciado en filosofía por la UCA y Maestro en Ciencias Sociales por la FLACSO-México. 


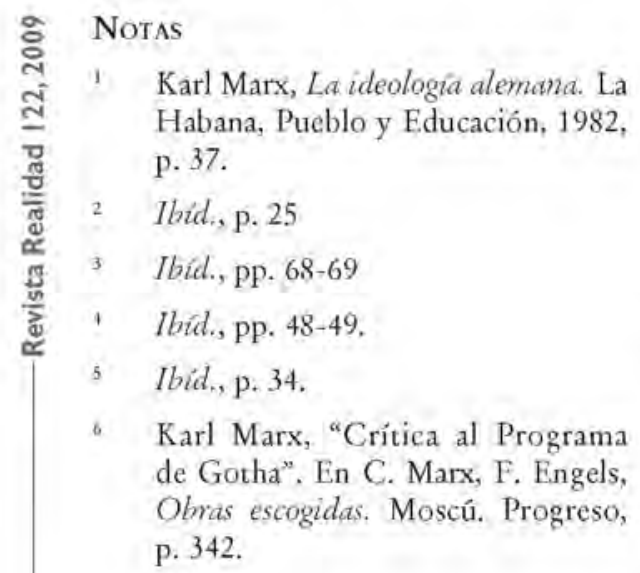

7 Ibid.

8. Karl Marx, La ideologza..., p. 33.

* Antonio Gramsci, Antología (selección, traducción y notas de Manuel Sacristán). México, Siglo XXI, 1981,291 .

10 Tlid., p. 402.

1) Cfr, Carlos Reynoso, Complejudady caos. Una exploración antropológica. México, UNAM, 2006, pp. 23-94; Mario Bunge, Emergencia y convergencia. Barcelona, Gedisa, 2003, pp. $45-110$.

12 Mario Bunge, Emergencia..., p. 49. 